\title{
Effects of Economic Growth on the Environment in the Congo: The Case of Air Pollution.
}

\author{
Lauric Ngouembe*, Eulalie Rose Abvou Ndombi, Jean Anaclet Mampassi
}

Université Marien Ngouabi De Brazzaville

Corresponding author: ingouembe@gmail.com

Received 01 November 2020;

Accepted 07 November 2020;

Published 01December 2020;

\begin{abstract}
The purpose of this study is to examine the effects of economic growth on the environment in the Republic of Congo. The analysis was based on the validity of the Kuznets environmental curve. For this purpose, the Johansen co-integration test (1988) and the VECM model were used over the period 1971-2014. The results of the study show that there is a long-term relationship between $\mathrm{CO}_{2}$ emissions and GDP. This last relationship suggests that in the long run, there is a Kuznets environmental curve in the Republic of Congo.
\end{abstract}

Keywords: Economic growth, Environment, Congo

JEL classification: F43, Q51, 055

\section{Introduction}

In countries with an old industrial tradition, demonstrations abound to denounce the nuisances engendered by economic activity, which reached a serious threshold. In recent years, society as a whole has struggled to question the vital concerns raised by the scientific community about environmental concerns. These questions were the subject of particular attention during major international meetings such as the first "Earth Summit" (held in Rio in 1992) and the recurrent conferences of the parties to the United Nations Framework Convention on Climate Change (the most recent of which - COP 24 - was organised in Katowice, Poland, in 2018).

As a result, the transmission to future generations of a highly degraded natural environment that allows the functioning of their economic and social ecosystems becomes an essential condition for sustainable development. Therefore, the major problem is to find an optimal balance between growth and the environment. The place of the environment in economic growth strategies has become a major concern. Ecological disasters, river pollution, acid rain, toxic clouds, nuclear accidents, etc. gradually integrate collective memory (Yachir, 1992).

Since its inception, globalization has contributed to the degradation of the environment through the exploitation of natural resources or the increase in international traffic due to the internationalization of production processes. The ecological impact of this globalisation is hard to determine, despite its consequences on many economic phenomena: international specialization, production relocation, trade development, technology transfer, growth and competition.

The question of economic growth through the increase in the production scale and its implications for the environment is recurrent and occupies a prominent place in recent economic literature. In other words, the fundamental problem is that of the existence of a causal link between these economic phenomena and the environment. At the outset, we can safely affirm that there is no obvious answer to this question; because many economic mechanisms, with contradictory effects, act on the environment at the local, regional, and global levels.

Economic actors only discover the relationship between the environment and growth as environmental constraints appear, as soon as the degradation of one of the functions below no longer allows an identical progression of the economic activity. According to Guillaume Gaulier and Nina Kousnetzoff (2007), these are three indispensable functions that the natural environment fulfils for the maintenance of life in general and economic activities in particular: (i) the resource reserve function; (ii) the discharge function: the absorption of waste by the air, water and soil; (iii) the function of vital habitat services: the air, water and the ozone layer in the upper atmosphere.

These two authors claim that only when the scarcity of a resource the degradation of landfill functions or habitat services results in a loss to the producer or the consumer does one begin to attach a price.

The first environmental constraint economists have been concerned about is the amount of farmland that classical economists of the nineteenth century consider to be an essential factor of production. They are worried about its limited nature, facing a growing population.

In the 20th century, while the discovery of chemical fertilizers greatly increases the yield of agricultural land, a new concern is the risk of subsurface resource depletion (fossil fuels, metals, etc.) From the 1970s, to the fear of the depletion of mineral raw materials is added the awareness of the overexploitation of natural resources with free access (forests, fishery resources...) and the saturation of the function of waste recycling by the environment, first observed at the local and regional levels (urban pollution, acid rain...), then at global level (climate change).

Beginning in the 1980s and especially in 1990s, there has been concern about the effect on human activities of the substantial and 
largely irreversible loss of biodiversity, that is to say, the deterioration of natural habitat services, be they vital (in developing countries) or amenable (in developed countries).

In view of the above, the purpose of this article is to analyze the effects of economic growth on the environment. Therefore, the central question that underlies the issue of this paper is: what are the effects of economic growth on the environment in the Congo? As the country is dependent on primary type specialization with a high concentration of oil and timber activities, it is argued that economic growth has long-term adverse effects on the environment.

The rest of this paper is structured as follows: the stylized facts of air pollution in the Congo are presented in the second section; the third section is devoted to the review of literature; the methodology is presented in the fourth section and the results and their interpretations are the subject of the fifth section; finally, the sixth section addressed policy findings and implications.

\section{Stylized facts of air pollution in the Congo}

The purpose of this section is to provide a report of the correlation between the creation of wealth and the production of greenhouse gases in the Congo.

Located in the western part of Central Africa, Congo has a predominantly oil exporting economy. After a period (1960-1974) when the economic activity was based mainly on the exploitation of wood, potash and, more marginally, on the agricultural production of food and export (coffee and cocoa), the Congolese economy has diversified very little since then and is largely dependent on oil (PND, 2012-2016). This predominance of oil has made the Congolese economy vulnerable to external shocks. The analysis in graph 1 below shows that during the period 1980-1984, the Congo experienced significant economic growth, reaching its highest level in 1982, with an average annual growth rate of $14.1 \%$.

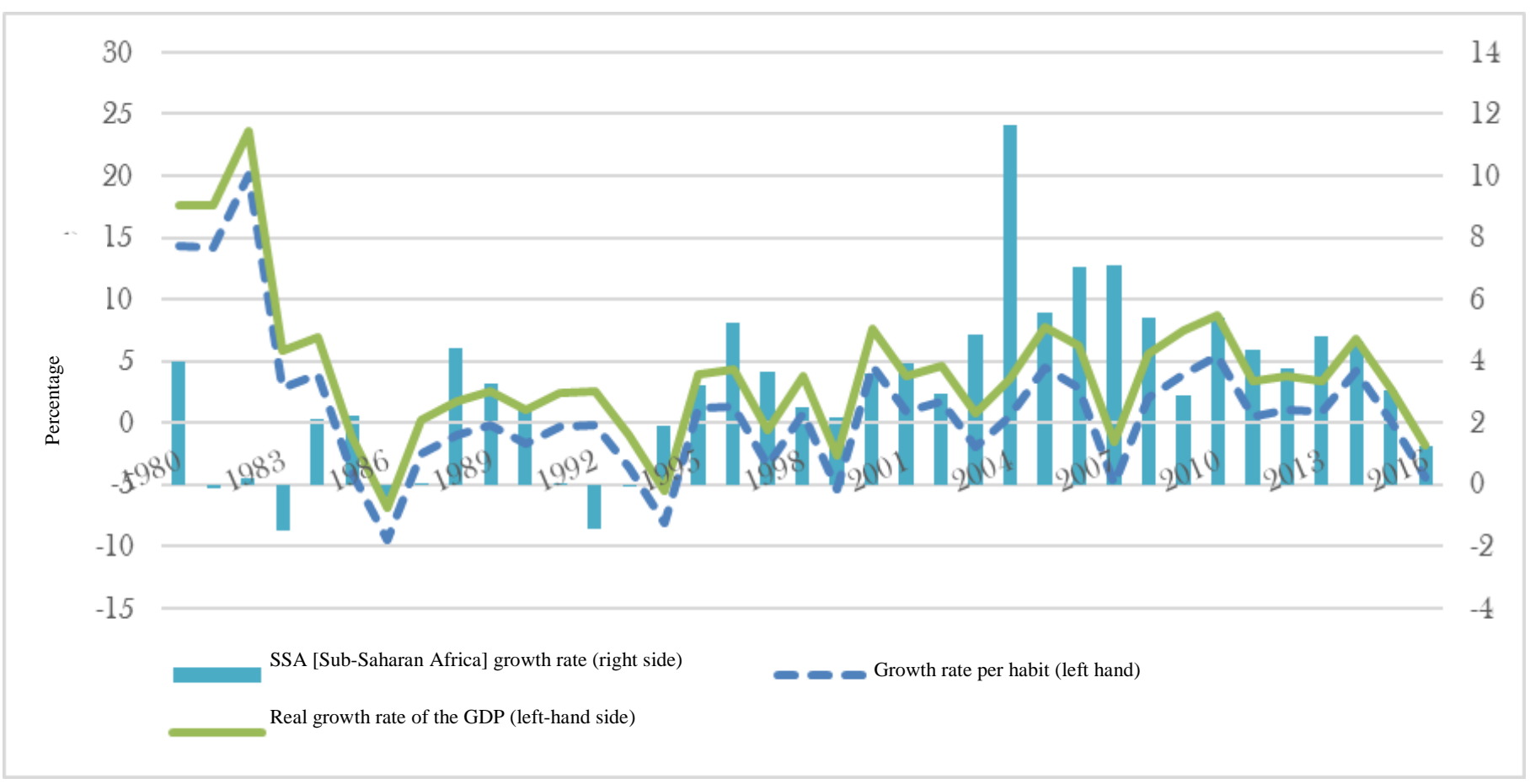

Graph1: Evolution of real GDP growth and GDP per capita

\section{Source: Authors from World Bank Data, World Development Indicators 2017}

This two-digit growth rate is mainly explained by the intensification of oil development, which has led to profound changes in the structure of the gross domestic product, exports and government revenues.

A comparison with the countries of Sub-Saharan Africa (SSA) also shows that the country's growth profile is more important. From 1985 to 2000, the evolution of the economic growth rate was less noticeable compared to the previous period. Indeed, the average annual growth rate represented only $0.7 \%$ over the 1985 2000 periods. This downturn in economic growth could be explained, in part, by the economic and political instability experienced by the country. From 2001 to 2010, the Congolese economy saw a slight increase in its GDP growth rate with an average annual growth of $2.9 \%$ over the period. This performance reflects the expression of: (i)the progressive consolidation of peace, (ii) a favorable international oil situation, and (iii) an increase in local oil production.

Also, this performance places Congo slightly above the average of Sub-Saharan African countries. Finally, the Congolese economy has experienced an average annual growth of $3 \%$ over the period
2011-2016. This performance, however, remains well below the target $(8.5 \%)$ desired in the National Development Plan (PND, 2012-2016).

However, despite this recovery in growth between 2013 and 2014 , the Congolese economy was marked by a sharp deceleration of its growth rate in 2015 (2.6\%), before plunging in 2016 (-1.8\%), mainly because of falling oil prices

Like [many] developing countries, the Congo is experiencing significant economic and demographic development anchored in the context of global warming. As such, data from the International Energy Agency suggest an increase in its energy consumption, correlated to that of its population. Energy consumption was estimated at about $220.06 \mathrm{~kg}$ of oil equivalent per capita in 2000. It reached $539.53 \mathrm{~kg}$ of oil equivalent per capita in 2014, an increase of $145 \%$. In addition to the $\mathrm{CO} 2$ emissions induced by this type of energy, the increase in consumption would have a major economic impact, since the hydrocarbon industry is still the main economic engine of the country. In fact, the hydrocarbons sector represents $82 \%$ of export earnings during the 2003-2008 period and 76\% for the 2009-2013 period (World Bank, 2015). 
With regard to the car fleets, second-hand vehicles (massively imported from Europe) estimated at more than 110,560 vehicles in 2014, are mainly responsible for air pollution in Brazzaville (INS, 2014).

The analysis of $\mathrm{CO}_{2}$ emissions by main fuels reveals that the consumption of natural gas remains the main source of $\mathrm{CO}_{2}$ emissions (see graph 4 below). It actually accounts for $65.18 \%$ of total emissions in 2015 , followed by oil $(34.82 \%)$.

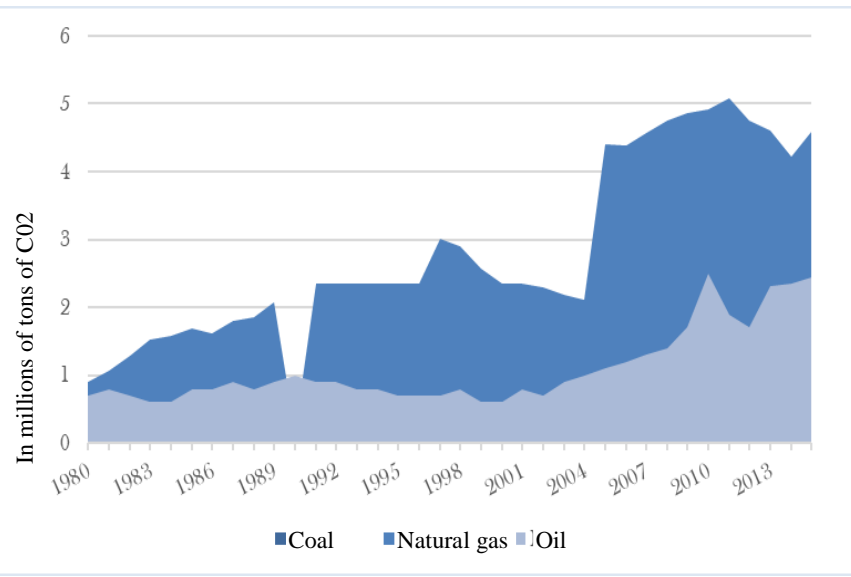

Graph 2: Evolution of $\mathrm{CO}_{2}$ emissions by fuel

\section{Source: Authors' calculations based on data from the} International Energy Agency (IEA)

Coal consumption is zero over the entire study period. This situation could be explained by the absence of coal mining in the country.

The $\mathrm{CO}_{2}$ from natural gas showed a downward trend in 1990 compared to 1989, from 2.07 million tonnes of $\mathrm{CO}_{2} 1989$ to 164,120 thousand tons of $\mathrm{CO}_{2}$ in 1990 .

\section{Literature paper}

The relationship between economic growth and the environment has been the subject of several studies. In this section we distinguish between theoretical work and empirical work.

\section{Economic growth and the environment in the theoretical literature}

The theoretical and empirical relationship between growth and the environment is the subject of divisions between economists from diametrically opposed philosophical points of view: a group called "optimists" and the other, "pessimists", nourishing the debates on the nature of this relationship from the beginning to the present day. In other words, it is about presenting the way in which the "optimists" and "pessimists" respectively address the positive (and/or negative) effects of growth on the environment.

On the theoretical level, the "optimists" are included after the Physiocrats (property wealth) and Adam Smith (1776) for whom the land is conceptualized in economic analysis as a limited natural market resource in quantity that can be appropriated. Unlike the Physiocrats, with the classical school of thought, wealth is no longer related to real estate, but it is produced, and it is real because the exchange value of a good is determined by the amount of work necessary for its production. The effect of the creation of wealth on the environment is manifested by the decreasing accumulation of "land" capital over time, and the use of less and less fertile land. The difference in the production price is thus determined by the difference in land quality, due to diminishing returns in agriculture, which results in the reduction of long-term profit. The environment (fertile land) therefore has a limiting effect on the creation of wealth.

Indeed, for the classical theory of international trade, the liberalization of trade behind globalisation leads each country to specialize in the production for which it has the greatest comparative advantage or the least disadvantage (David Ricardo, 1817). As well, the works of Hotelling (1931) and Pigou (1920) support the effects of production activity externalities on the environment.

Thus, the first classical economists integrate into their concept the importance of the relationship between economic growth and the environment (materialized by natural resources). In other words, some countries would specialize in the extraction of raw materials or the production of agricultural goods, which leads to an intensive exploitation of natural resources. It takes many forms (deforestation, monoculture, the destruction of habitats of rare species, etc.), which are attacks on biodiversity and therefore on the environment. Indeed, trade liberalization has a positive effect on economic growth for all the countries taking part in these exchanges, which, in turn, has negative or positive effects on the environment depending on the level of development of the country (Grether and Melo, 2003).

In addition, a group of "optimistic" researchers called "Club de Rome" (1972) considers that if current trends (economic and environmental) continue, in the medium term the depletion of most natural resources will be certain, which will diminish or even eliminate the possibilities for future growth. According to these researchers (Meadows et al., 1972, 1992, 2004), exponential economic growth in a finite world, due to the intensive exploitation of natural resources, would lead to an eventual collapse of the system. In other words, the path to a steady economic state is inevitable. This debate on the relationship between economic growth and the environment will experience a new dynamic, with the progressive affirmation and renewal of much more radical hypotheses such as those of decline.

The hypotheses of decay, of classical inspiration (in particular with Malthus, Ricardo and Smill, who predicted a "stationary state"), have been developed among others in the work of economists such as Georgescu-Roegen (1995) and Daly (1974, 1993). By applying the laws of thermodynamics to economics, Georgescu-Roegen (1995) shows that usable energy is continuously transformed into unusable energy until it disappears completely.

In other words, for Georgescu-Roegen (1995), economic development cannot continue in a world where resources are limited. Furthermore, he considers that the land is a closed system, and even with zero growth the resources will eventually run out, certainly slowly but surely. As a result, future generations will inherit a natural heritage that is insufficient for their needs.

A second group of "optimistic" authors (Martinez-Alier, 1987), followers of the ecological economy whose analytical framework goes beyond that of the neo-classical economics and environmental economics, integrates the economic system into a broader systemic set (land or biosphere).

In fact, the work on the Kuznets environmental curve immediately corroborates the "optimistic" approach, when they claim that growth degrades the environment in the early stages of development, and then improves it starting at a certain income level. In other words, this increasing or decreasing relationship, in the form of an inverted $U$ curve, between the level of per capita income and the level of environmental degradation, depends on the 
type of pollution or each of the functions of the environment and the location of the growth effects. Thus, the inverted $U$ curve clearly shows the evolution of sulphur dioxide and nitrogen dioxide emissions, and for suspended particles, compared to the level of per capita income (Frankel and Rose, 2005). However, the work on the Kuznets environmental curve also demonstrates the ambiguity of cross-border and global pollution. They show that this relationship between growth and the environment appears even more contrasting for carbon dioxide (CO2) emissions in developed countries. Thus, they are an extension of the standard neoclassical approach, particularly the work of Hotelling (1931) and Pigou (1920). The creation of two branches of the environmental economy (the economy of natural resources and the economy of the environment) which result therefrom, integrates the environmental problems within the framework analysis methods of the neoclassical economy of the growth.

For "pessimistic" authors, especially the neoclassical school, unlike the classical school, the relationship between the economy and the environment is much less important. First, in neoclassical economics, land appears, as much as other natural resources, as an asset having a price and replaceable by labor and/or capital. Second, these natural resources (including land) are considered as already incorporated into the capital factor (Faucheux and Noel, 1995). In fact, neoclassical authors break with the classical hypothesis of a single factor of production for two perfectly substitutable factors (capital and labor) (Hotelling, 1931, Solow, 1974 and Hartwick, 1977), used by the standard neoclassical production function. (Cobb-Douglas).

Neoclassical authors provide a new explanation of the possible origin of the comparative advantages which stem from differences in factor endowments between countries, under the assumption of the immobility of these factors at the international level (Heckscher- Ohlin). On these grounds, capital-intensive countries would specialize in producing goods that are more capital-intensive than labor-intensive. Conversely, countries whose main endowment is labor will benefit from comparative advantages in labor-intensive production.

As early as the 1930s, the so-called economy of natural resources (analysis of the exploitation of exhaustible resources Hotelling, 1931) - and the economy of the environment (welfare economics and the internalization of externalities - Pigou, 1920). The place of the environment and natural resources momentarily evaded in the neoclassical theory, finds a renewed interest with Solow (1991) for which the marketable natural resources (exhaustible, but also renewable) are considered as a specific capital (natural capital).

In other words, these "pessimistic" authors minimize the current environmental effects of economic growth and believe in the reversal of the trend towards the scarcity of natural resources, thanks to the development of alternative resources using technological solutions, and to the increase in the price of exhaustible resources. In addition, they support a positive correlation between economic growth and the quality of the environment from a certain development level.

\section{Economic growth and the environment in the empirical literature}

Empirically, the different studies of the effects of economic growth on the environment make it a core issue in the economy of the environment, despite the heated controversy they face.

Kuznets (1955), looking at the link between the level of inequality and economic development in a country, finds an inverse "U" relationship between the per capita income and the level of environmental pollution. Several empirical studies based on the verification of Kuznets Environmental Curve (KEC) are emerging.

Economists such as Grossman and Krueger (1991, 1993, 1995) and Panayotou (1993) first detect an "inverted U" curve between per capita income and concentrations of certain air pollutants $\left(\mathrm{CO}_{2}\right.$, $\mathrm{SO}_{2}, \mathrm{NO}_{\mathrm{x}}$ ). They tested the environmental impacts of the North American Free Trade Agreement (NAFTA) in a panel. The environmental variables taken into account are sulphur dioxide $\left(\mathrm{SO}_{2}\right)$ and suspended particulate matter (SPM). They find that the turning point for $\mathrm{SO}_{2}$ is between US $\$ 4,000$ and US $\$ 5,000$ per capita. However, this turning point is much lower for suspended particles. They make it clear that the environmental pollution of the countries increases with the level of economic development of these countries; this because of the opening of the market and the increase of economic activity because industrialization would impose a significant pressure on the environment. Finally, at a certain income level, the relative increase in the importance of services to the GDP of economies and the awareness of environmental consequences will tend to reduce environmental degradation.

The work of Asif and Muneer (2007) shows that in developed countries (OECD), energy consumption increases on average by $1.1 \%$ per year. Emerging economies as a whole are expected to have their primary energy consumption grow at an average annual rate of $3.2 \%$ until 2025. In addition, the International Energy Agency (IEA) is forecasting strong growth in global energy demand by 2025 . This is alarming when fossil fuels account for $80 \%$ to $95 \%$ of global demand for primary energy. This high dependence increases the risk of a possible energy "blackout", which could be caused by the depletion of these natural resources.

In addition Fullerton et al. (2009) show that automobile pollution constitutes a danger in areas with high human and economic activity. In Africa, the work of Tohon et al. (2014) show that the development of road transport accounts for more than $90 \%$ of the movement of people and more than $75 \%$ of goods traffic. According to Savy (2008), transport accounts for $21 \%$ of all greenhouse gas (GHG) emissions globally, and road transport alone accounts for $93 \%$ of total greenhouse gas emissions related to transport. It is therefore an important source of air pollution.

Armeanu et al. (2018) use the panel data by estimating three (03) models from a sample of 28 countries of the European Union (EU) for the period 1990-2014. The results of the first model, relating to the OLS [ordinary least squares] regression, and the second model (that of the fixed effects regression). Finally, under the panel error vector model, the authors end up with a one-way short-term causality ranging from GDP per capita growth to greenhouse gas emissions, as well as a bidirectional causality between primary energy consumption and greenhouse gas emissions.

Najid et al. (2016) investigated and validated the existence of an inverted $\mathrm{U}$ shaped relationship between $\mathrm{CO}_{2}$ emissions and longterm economic growth in Croatia for the period 1992-2011.

In addition to panel data and the time series, other work, such as Berrens et al. (1997), were based on cross-section series and sought to test the CEK hypothesis for the United States; considering municipal waste as an environmental indicator. By adopting the generalised Gamma function as an alternative to the standard polynomial function, this work concluded that there is an inverted U curve with a turning point around US $\$ 20,000$ per capita.

However, there is still controversy about the validity and existence of such a relationship (Stern, 2003). While a number of 
existing studies agree on the pollutant nature of economic activity in the early stages of development by providing empirical evidence in favor of the CEK hypothesis, other studies are finding contrasted results.

The work of Meunié (2004) notes that not only is this curve detected for some pollutants with localized effects but even in this case many methodological criticisms weaken its scope.

By adopting the ARDL model, Acaravci et al. (2010) analyzed the CEK hypothesis for $\mathrm{CO}_{2}$, economic growth and energy consumption. The sample is composed of $19 \mathrm{EU}$ countries. The results obtained by the authors make it possible to reject the CEK hypothesis.

In the specific case of Qatar, Mrabet et al. (2017) used the ARDL method for the 1980-2011 period and rejected the CEK assumption when using carbon dioxide emissions, but confirmed the CEK using the ecological footprint as an environmental indicator.

Selin and Ozdemir (2017), for their part, have focused attention on the relationship between, on the one hand, $\mathrm{CO}_{2}$ emissions and income and, on the other hand, $\mathrm{CO}_{2}$ emissions income and energy consumption as environmental indicators. Using panel data, they considered 26 OECD countries for the year 1980 and 52 emerging countries for the year 2010. The results of both models show that the curve takes the form of an inverted " $\mathrm{N}$ " for the cubic functional form. Thus, the results do not confirm the CEK hypothesis. This implies that the degradation of the environment cannot be automatically solved by economic growth.

In view of the above, we ask ourselves the following question: how large are the effects of economic growth on air pollution in the Congo? The overall objective of this study is to analyze the effects of economic growth on air pollution in the Congo while verifying the hypothesis that there is a Kuznets environmental curve in the form of an inverted $\mathrm{U}$ between economic growth and $\mathrm{CO} 2$ emissions in the Congo.

\section{Methodology}

The purpose of this section is to present the econometric model specification, the source of the data used and the model for estimation purposes.

\section{Specification of the theoretical model}

The formulation of the analysis model of the effect of growth on the degradation of the environment in the Congo follows from the STIRPAT model, which was initially proposed by Dietz and Rosa (1997) to analyze the effects of the driving forces or activities on the environment.

The STIRPAT model is given by:

$$
\boldsymbol{I}=\alpha \boldsymbol{P}^{\beta} \boldsymbol{A}^{\gamma} \boldsymbol{T}^{\delta}
$$

Where $P, A$ and $T$ represent population, wealth and technology respectively. Moreover, $\boldsymbol{\alpha} . \boldsymbol{B} . \mathbf{V}$ and $\delta$ are parameters to be estimated.

By passing logarithmic quantities on both sides of the equation(1) , we obtain:

$\ln I=\alpha_{0}+\beta \ln P+\gamma \ln A+\delta \ln T$
Where $\alpha_{0}=\ln \alpha$

York et al. (2003) also investigated the introduction of additional variables such as institution-related variables and squared variables to measure non-linearities in the model. They lay the foundation for the specification of the model we apply:

$$
\ln C O_{2}=\alpha_{0}+\alpha_{1} \ln P+\alpha_{2} \ln P I B+\alpha_{3} \ln P I B^{2}+\alpha_{4} \ln I N D
$$

Where the dependent variable in (3) corresponds to $\mathrm{CO} 2$ emissions per capita, measured in metric tons per capita. The GDP and GDP2 variables represent the cornerstone of the KCE analysis. The term "squared" takes into account the non-linearities of the pollutionincome relationship. As an indicator of technological progress, we use industrial activity (IND) calculated by the share of the manufacturing industry in the total GDP. In addition, the population effect is shown through the growth indicator. That being said, integrating the population back into the model can cause an endogeneity problem. Also, the size of the population influences the environment only through the consumption of energy. In this logic, energy consumption is used in this model as a proxy for environmental pollution attributable to the size of the population.

The equation (3) is thus logarithmic (3.1) in the empirical model section below.

\section{Model for estimation purposes}

In the wake of previous analyses, this work follows the methodology of recent studies carried out on the "economic growth - environmental pollution" nexus (Soytas et al., 2007, Ang, 2008), also integrating energy consumption and foreign trade as explanatory variables.

Thus, the equation (3) becomes:

$$
L C O_{2_{t}}=\alpha_{0}+\alpha_{1} L C E_{t}+\alpha_{2} L P I B_{t}+\alpha_{3} L P I B_{t}^{2}+\alpha_{4} L I N D_{t}+\alpha_{5} L O C_{t}+\varepsilon_{t}
$$

\section{(3.1)}

With $\varepsilon_{t}$ the term of error.

The variables of the model that we used in this study based on our literature review are as follows:

The endogenous variable is the emission of $\mathrm{CO}_{2}$ measured in tons of kilograms per inhabitant; it evaluates the impact of the environmental restriction on economic growth. This same indicator was used by Trotignon (2011) to analyze the impact of $\mathrm{CO}_{2}$ restrictions on the exports of certain emerging countries. The variable of interest is the GDP per capita: It is expressed in US dollars (at a constant price in 2010). According to the economic literature, one should expect a significantly positive coefficient for its linear term and a significantly negative coefficient for its quadratic term, a necessary condition for obtaining a concave form of the CEK as emphasized by Grossman and Krueger (1995). Energy consumption (EC): expressed in $\mathrm{kg}$ of oil equivalent per capita, it was also used in the works of Soytas et al (2007) and Ang (2008). Industrial sector share (IND) in the GDP: Expressed as a percentage of the total GDP. For Arrow et al (1995). The degree of openness of the economy (OC): This degree of openness measures the place of the external environment (other economies) in the national economy. 
The data used in this research are of an annual periodicity and range from 1971 to 2014 . They are obtained from the database of the World Bank, available on the website

www.databank.worldbank.org.

The validation of the error correction vector model is performed on the basis of the same tests as in the multiple linear model (normality, autocorrelation stationarity test, coefficient stability, etc.) The optimal delay and the cointegration rank being of order 1 ,

\section{Estimation results}

The results derived from the estimation of our model are based on three points: the results relating to the adjustment towards the longterm target of the model, the results of the estimation of the shortterm model and the results of the estimation of the long-term model, whose associated coefficients are contained in the tables below:

Table1: Adjustment speed towards the long-term target

\begin{tabular}{|l|l|l|}
\hline Variables & Coefficients & T-statistics \\
\hline D(LCO2(-1)) & -0.372675 & {$[-2.83084]$} \\
\hline
\end{tabular}

Source: Authors from the results obtained on STATA.

Table2: Results of the estimation of the short-term model

\begin{tabular}{|l|l|l|}
\hline Variables & Coefficients & T-statistics \\
\hline D(LCO2(-1)) & 0.059802 & {$[0.36571]$} \\
\hline D(LCE(-1)) & -0.153361 & {$[-0.24754]$} \\
\hline D(LOC(-1)) & 0.264822 & {$[0.34595]$} \\
\hline D(LIND(-1)) & -0.008133 & {$[-0.0193]$} \\
\hline D(PIB0-1)) & 0.646971 & {$[2.56996]^{*}$} \\
\hline D(PIB20(-1)) & -0.112371 & {$[-2.37600]^{*}$} \\
\hline
\end{tabular}

Note: * significant at the 5\% threshold

Source: Authors from the results obtained on STATA.

Table3: Results of the estimation of the long-term model

\begin{tabular}{|l|l|l|}
\hline Variables & Coefficients & T-statistics \\
\hline LCE & -2.1604 & $-2.68976^{*}$ \\
\hline LOC & -7.4817 & $-5.54335^{*}$ \\
\hline LIND & 4.6569 & $5.88289^{*}$ \\
\hline PIB0 & 1.8135 & $3.55663^{*}$ \\
\hline PIB20 & -0.4222 & $-4.11345^{*}$ \\
\hline
\end{tabular}

Note: * significant at the $5 \%$ threshold

Source: Authors from the results obtained on STATA.

Reading Table 4 shows that only the model where $\mathrm{CO}_{2}$ is the explained variable can be retained for the purposes of interpretation. Indeed, its restoring force is negative and significant at the threshold of 5\%. This result confirms the character of the approach based on error correction; which justifies the existence of an adjustment relation towards the long-term equilibrium in the case of this study. Moreover, the coefficient of determination of this model is 0.3843 (Appendix 4) which means that the $\mathrm{CO}_{2}$ variations in the Congo are explained by the fluctuations of our exogenous variables by $38.43 \%$. Note that this small percentage is due to the omission of certain variables that could also influence $\mathrm{CO}_{2}$ emissions in the Congo, such as demography, which is also an important element determining the quality of the environment. However, the strength of this model is also due to the fact that the LM test of autocorrelation (Appendix 1) of residuals of the regression confirms the absence of error autocorrelation. Beside this, the Jarque-Bera test (Appendix 2) shows that the latter follows a normal distribution All in all, the model has good statistical properties. Therefore we can proceed to the interpretation of the results.

\section{Interpretation of the results}

The results obtained from the estimation of the econometric model of this study (VECM) allow us to draw a single major conclusion, namely, that there are non-linear effects of growth on the environment in the Republic of Congo.

\section{Existence of a non-linear relationship}

The validation of the CEK assumption in the Congo and the fact that the coefficients associated with GDP ( and GDP squared) are not too low, allow us to calculate the turning point corresponding to the per capita income from which $\mathrm{CO} 2$ falls. The formula for calculating this point is as follows:

$$
X^{*}=\exp \left[-\left(\frac{\alpha 2}{2 \alpha_{3}}\right)\right]
$$

Considering the results of Table 6 we have:

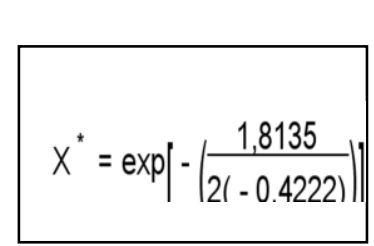
$=$ US $\$ 1.46$ From the above the CEK can be graphically illustrated as follows:

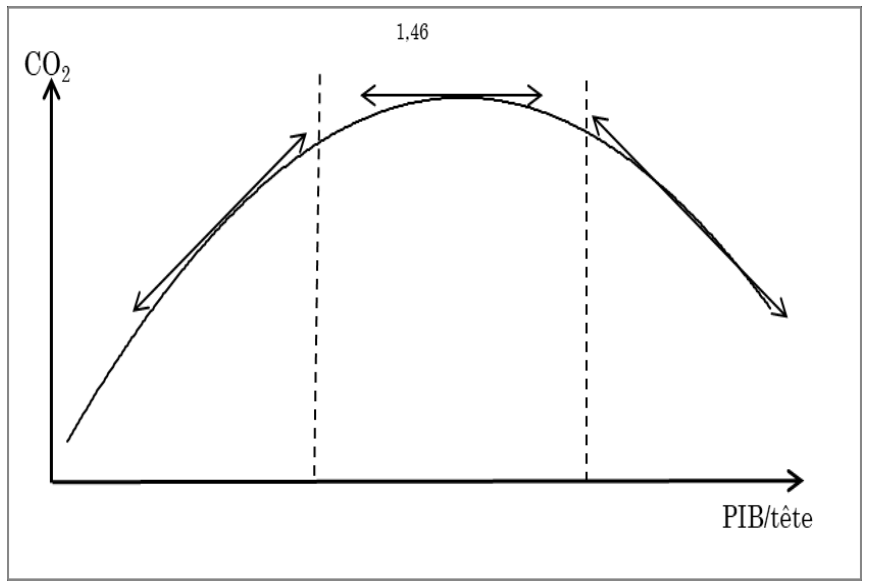

Following the results of the long-term model, we find that the parameters associated with the GDP and GDP squared variables are significant at the 5\% threshold and [they are] expected signs. These results confirm the logic of the Kuznets model, which assumes a positive sign for the linear term (GDP) and a negative sign for the quadratic term $\left(\mathrm{GDP}^{2}\right)$, as a necessary condition for obtaining a concave shape of the Kuznets environmental curve.

As a result, the results confirm our CEK hypothesis that the level of $\mathrm{CO}_{2}$ emissions initially increases with income then stabilizes before declining when the country reaches high income levels. Thus, in the long term, there is a Kuznets environmental curve in the Congo in the shape of an inverted "U".

In addition, these results are similar to those of Abdul and Mahmud (2009) who found an inverted U-shaped relationship between $\mathrm{CO}_{2}$ emissions and economic growth in the case of China, with energy consumption and international trade as control variables. But they contrast with those of Selin and Ozdemir. 
(2017), who found an inverted "N" shape relationship for the cubic functional form.

Furthermore, these results highlight the possibility of an almost perfect substitutability between natural capital (natural resource) and artificial capital (created resource), supported by the theory of sustainability (Pigou, 1920; Coase, 1960; Solow, 1974; and Hartwick, 1977), which suggests that environmental regulation will depend, beyond a certain threshold, on the use of economic instruments and a service economy to improve the quality of the environment.

The existence of a Kuznets environmental curve for the Congo case is not a surprise because this result is in line with that expected for developing countries. The elements of the explanation are to be found in the structure of the Congolese productive system. In fact, the oil exploitation that began in the mid-1970s led to deep changes in the structure of the GDP and the environment. In the wake of these changes, the development of the industrial sector and the intensification of the exploitation of natural resources have led to an increase in air pollution, the destruction of aquatic fauna and coastal ecosystems, deforestation, climate change (PND, 2012-2016). This is the first (upward) phase of the Kuznets (CEK) environmental curve in the Republic of Congo.

On the other hand, with the implementation of sustainable development objectives in which the Congo is a stakeholder, taking into consideration environmental concerns is increasingly integrating the development process in the Republic of Congo. Thus, adopted environmental policies, the most recent in the PND (2012-2016) following performance carried out in terms of growth will favor the downward phase of the CEK, justified by the decrease in $\mathrm{CO}_{2}$ level because only the actual observations of the future values of $\mathrm{CO}_{2}$ emissions could confirm this categorically since the Congo, like most developing countries, is located on the growing part of the Kuznets environmental curve. Indeed, the positive sign of the per capita income coefficient and the negative sign of the quadratic term of the per capita income coefficient validate the existence of the CEK, but the turning point is too high and is therefore unachievable.

For Congo, the turning point is US $\$ 1.46$ per capita, far from being impossible. This simply refers to the inaccessibility of this point at the moment. In addition, this result coincides with that of Bella et al. (2010). Indeed, in their study, these authors found that the results from the CEK estimate in non-OECD countries between 1971 and 2006 showed significant coefficients with the expected signs, but the turning points were not accessible. In the same vein, Coulibaly S. (2014), within the framework of his thesis entitled "Energy, growth and environment in the WAEMU [West African Economic and Monetary Union] countries" found inaccessible turning points for the case of Benin, Côte d'Ivoire and Senegal, respectively of $6.57 \times 1018$ US dollars per capita for the first, $2.38 \times 1012$ US dollars per capita for the second and finally $4.09 \mathrm{x}$ 1027 US dollars per capita for the last one.

\section{Conclusions and policy implications}

The main objective of this study was to examine the effect of economic growth on the environment through an analysis of the validity of the Kuznets (CEK) environmental curve for the Congo for the 1971-2014 period. The CEK hypothesis was investigated using the Vector Error Correction Approach (VECM) and considering $\mathrm{CO}_{2}$ emissions per capita as an indicator of environmental conditions.

The empirical results confirm the presence of a strong long-term relationship between $\mathrm{CO}_{2}$ emissions per capita and the GDP per capita. Moreover, the positive sign of the coefficient of the latter and the negative sign of the coefficient of the quadratic term of the GDP per capita validate our hypothesis of the existence of the CEK for the case of Congo.

In the Congolese context, these results show that policies of economic expansion must be accompanied by those fostering better management of the environment in order to improve the standard of living of the population and the eradication of poverty in accordance with International Conventions and Treaties especially related to Sustainable Development Goals (SDGs).

\section{References}

[1] Acaravci, A. et Ozturk, I. (2010), «On the relationship between energy consumption $\mathrm{CO} 2$ emissions and economic growth in Europe », Energy, Vol. 35, No. 12, pp. 5412-5420.

[2] Ang, J. (2008), « Economic development, pollutant emissions and energy consumption in Malaysia ». Journal of Policy Modeling, Vol. 30, No. 2, pp. 271 278.

[3] Armeanu, D. et al, (2018), « Exploring the link between environmental pollution and economic growth in EU 28countries: Is there an environmental Kuznets curve? », journal pone Vol.13, No.5, pp.10-1371.

[4] Arrow et al. (1996), « Economic growth, carrying capacity and the environment », Ecological Economics, Vol. 268, pp. 520-521.

[5] ASIF, M. et Muneer, T. (2007), « Energy supply, its demand and security issues for developed and emerging economies ». Renewable and Sustainable Energy Reviews, Vol. 11, No. 7, pp. 1388-1413.

[6] Banque Mondiale (2010), Rapport sur le développement dans le monde 2010 : Développement et changements climatiques, Washington, DC 20433, Etats Unis d'Amérique.

[7] Banque Mondiale (1992), Rapport sur le développement dans le monde, le développement et l'environnement . Oxford University Press.

[8] Berrens, R., Bohara, A., Gawande, K., Wang, P., (1997), «Testing the inverted U-hypothesis for U.S. hazardous waste: an application of the generalised Gamma model », Economic Letters Vol.55, pp.435-440.

[9] CMED, (1987), « Commission mondiale sur l'environnement et le développement ». Rapport Brundtland. Notre avenir à tous, Fleuve

[10] Coase, R., (1960), "The Problem of Social Cost $\neg$ », Journal of Low Economics, Vol. 3. No.1.

[11] Daly, H. (1974), « The Economics of the Steady State », American Economic Review, Vol. 64, No. 2, pp. 15-21.

[12] Faucheux S. et J-F Noel (1995) : Economie des ressources naturelles et de l'environnement, Armand Collin.

[13] Georgescu-Roegen, N, (1979), «Demain la décroissance », Editions Pierre-Marcel Favre, Paris \& Lausanne, pp.157. (morceaux choisis d'écrits de NGR traduits par J Grinevald et I. Rens); réédité en 1995 sous le titre : « La décroissance. Entropie-Écologie-Économie » Editions Sang de la Terre, Paris, pp.254.

[14] GIEC (2014), « Climate Change 2014-Synthesis report ». Fourth Assessment Report. 
[15] Grether J.-M. et J. de Melo (2003), « Globalization and Dirty industries : Do Pollution Havens Metter?», NBER Working Paper 9776.

[16] Grossman, G., Krueger, A., (1995), « Economic growth and the environment », Quarterly Journal of Economics, Vol. 110 No. 2, pp 353-377.

[17] Grossman, G., Krueger, A., (1994), « Environmental Impacts of a North American Free Trade Agreement », National Bureau of Economic Research.

[18] Grossman, G., Krueger, A. et Alan, B., (1993), « Environmental Impacts of a North American Free Trade Agreement, in P. Garber, ed., The US-Mexico Free Trade agreement » MIT Press, pp. 13-56

[19] Grossmann, G., Krueger., (1991), « Environmental impacts of a North American free trade agreement, ». NBER Working paper, No.3914.

[20] Guillaume Gaulier et Nina Kousnetzoff : Economie mondiale 2007, La Découverte.

[21] Hartwick, J., (1977), « Intergenerational Equityand Investing Rents from Exhaustible Resources, » American Economic Review, Vol.67, No.5, pp. 972-974.

[22] Hotelling, H., (1931), « The Economics of Exhaustible Resources ». Journal of Political Economy Vol.39 No.2, pp.137.

[23] Johansen, S., (1988), « Statistical analysis of cointegrating vectors ». Journal of Economic Dynamics and. Control, Vol. 12, No. 2-3, pp. 231-254.

[24] Kuznets, S., (1955), «Economic growth and income inequality ». American Economic Review No.49, pp 128.

[25] Lin,et al.(2016) « L'hypothèse de la courbe environnementale de Kuznets est-elle une base solide pour la politique environnementale en Afrique? », J Clean Prod. No. 133, pp. 712-24.

[26] Meadows, H., Meadows D.L., Randers, J., Behrens, W., (1972), « The Limits to Growth ». Universe Books, New York.
[27] Mrabet, Z., et al, (2017) «Testing the Kuznets Curve hypothesis for Qatar: A comparison between carbon dioxide and ecological footprint. 》 RenewSustEnergRev.70:1366-75.

[28] Najid A., et al, (2016), "Modelling the CO emissions and Economic growth in Croatia: Is there 2 any Environmental Kuznets Curve? », energy. S03605442(16)31911-9

[29] Ozturk I, et Acaravci A, (2010), «CO2 emissions, energy consumption and economic growth in Turkey ». Renew SustEnergRev.Vol.14 No.9,pp.3220-5.

[30] Panayotou, T., (1993), « Empirical Tests and Policy Analysis of Environmental Degradation at Different Stages of Economic Development ». Working Paper WP No.238.

[31] Pigou A., (1920), « The Economics of Welfare ». London, McMillan, 4th edition, 1932.

[32] Solow, R., (1974), «the Economics of Resources or Resources of Economics ». The American Economics Review, vol. 64, No.2, pp. 1-14.

[33] Selin,Ö., Özdemir Ö., (2017), « Economic growth, energy, and environmental Kuznets curve. » Renewable and Sustainable Energy Reviews Vol.72, pp. 639-647.

[34] Stern D. et al., (1996), « Economic growth and environmental degradation: The Environmental Kuznets Curve and sustainable development ", World Development, vol. 24, pp. 1151-1160.

[35] Stern D (2003), "The Rise and the Fall of the Environmental Kuznets Curve », Department of Economics, Rensselaer Polytechnic Institute, working paper, No. 0302

[36] Soytas U., Sari R., Ewing T., (2007), « Energy consumption, income and carbon emissions in the United States ». Ecological Economics. Vol. 62, pp. 482-489.

[37] Trotignon J. (2011), « Restriction des émissions deCO2 et pays émergents : un "effet Porter" appliqué aux exportations ? ». Mondes en développement, Vol.2, No.154, pp. 45-64. 